\title{
Improvement of the training level of environmental professionals by environmental monitoring skill competition
}

\author{
Jing-Ping Wang, Xin-Hong Wang, Zheng-Hao Fei \\ School of chemistry and environmental engineering, Yancheng Teachers University, Jiangsu, 224007, China
}

\begin{abstract}
The cultivation of innovative technical practical ability is the essential work of environmental undergraduate professional education. Through the leading role of environmental monitoring skill competition in environmental monitoring courses, the course construction of environmental undergraduate majors is constantly promoted through competition to promote reform, construction and teaching, and the combination of teaching and competition, so as to enrich the content and form of course teaching and improve the professional level of professional teachers, so as to realize the overall improvement of the comprehensive quality of students majoring in environmental monitoring.
\end{abstract}

Keywords Environmental monitoring; Undergraduate education in environment; Skill competition; Curriculum construction

DOI: $10.7176 / \mathrm{JEES} / 9-2-09$

\section{Introduction}

For environmental engineering undergraduate education, skill training is an important part of training environmental engineering talents. For students majoring in environmental engineering, the skill level is a stepping stone for their job hunting. For enterprises, skill competition is an important means to evaluate and reserve skilled talents [1-2]. The "Anlailisi" water treatment experiment competition for college students in jiangsu province has been held for two times, and the "Pushi cup" environmental monitoring skill competition for college students in yancheng city has also been held for four times. The remarkable features of the competition items are the selection of reasonable and representative operation contents of the industry, the scientific and operable scoring rules, and the open form of organization and management, which provide an environment monitoring skill platform for students in environmental colleges and universities. It is important for us to take a deep investigation on how to optimize that construction of environmental monitor course by environmental monitoring skill competition and improve the overall teaching quality.

\section{The leading and promoting role of environmental monitoring skill competition}

It is that most recent change in the field of environment monitor skill in jiangsu normal university student "' Anlailisi "water treatment experiment competition and" pate cup "environmental monitoring skill competition in yancheng city. The skill competition is divided into the two parts of practical operation and theoretical examination, and the content set up is closely related to the actual work in the organized competition, which reveals the development changes in the field of environmental engineering. Through competition to promote the quality of talent training, the "sufficient and reasonable" principle of professional theory education is highlighted, which emphasizes the skill training of professional posts and encourages innovation. The competition promotes the establishment of cooperative relationship between engineering colleges and industry (enterprise) industry, and the skills competition will adopt the latest and hottest methods or technologies of the business (enterprise) industry in the content setting, and the scoring standard of the project is to follow the national professional standard or the line (enterprise) industry position standard ${ }^{[3]}$, and the school can meet the newly emerging industries and technologies in the related course setting and training content. It requires that schools have to be able to establish a relationship with the front of the line, and let the students know what it is to be an environmental monitor, and to understand the basic requirements of the business, and to meet the basic requirements of the professionals, to work with the school, to achieve the "zero distance" jobs of the environmental engineering students.

\section{Promote the construction of specialized courses driven by competitions}

The real role of the environmental monitoring skills competition is to provide direction for the reform and construction of the environmental monitoring course, which will give full play to the enlightenment guidance role of competition in the course teaching [4].

3.1 Conduct project-based course design under the guidance of competition In the environmental monitoring skill competition, skill projects are generally designed according to the actual 
needs of professional posts, and the tasks of jobs are taken as the criteria to determine the competition items and rules in combination with the industry development frontier and relevant national policies. In the process of professional group of curriculum construction can draw lessons from the practice of skills competition, according to task design curriculum content, implementation of project teaching method, the ability to work in accordance with the relevant industry and technical requirements to design the learning situation, training program, evaluation standard, teaching resources configuration, so that the students can learn to complete the work process. Such as held in 2016 in jiangsu province "Ann was made," a glass of water treatment experimental skills competition is "xuanwu hu water COD determination, competition consists of two parts, project design and field experiment, the scheme includes the stationing, field investigation, optimizing the water sample collection, preservation, pretreatment, sample analysis, data processing and analysis, quality assurance and control of environmental monitoring scheme designing, such as field experiment part is according to the working process of the environmental monitoring set game content, according to the sample analysis, choose COD analysis method, onsite operation, and evaluate the results of the analysis. In the scheme design, I consulted zhang liubin, the stationmaster of yancheng environmental monitoring center, to understand the surface water and sewage monitoring specifications and the "13th five-year" national surface water environmental quality inspection guidelines, to be familiar with the operation procedures of on-site monitoring projects, and to be familiar with the requirements for the pretreatment of monitoring projects and the selection of laboratory analysis methods. Be familiar with the representativeness, validity and completeness of samples collected. And the Internet to understand the "xuanwu lake" and the geographical location of the lake pollution, reasonable layout, and develop monitoring programs. Through the preparation of a complete program, students have gained a profound understanding and improvement of environmental monitoring, and at the same time, increased their interest in studying environmental majors and their sense of responsibility. Through the leading role of environmental monitoring skill competition, teachers can design relevant courses of environmental specialty group according to "project-based guidance".

\subsection{The competition promotes the continuous update of the course content}

Knowledge point of that competition of environmental monitoring skill are wide and the knowledge points are new, whereas the existing teaching material has the existence of a disconnection from the old and the theory and practice, which cannot suit the need of the knowledge depth and the breadth of the competition of environmental monitoring skills. Therefore, during skill training and competition based on the industry standard of environmental protection industry, the environment professional teacher continuously introduces the new knowledge, new method, new specification and new standard introduced in the course of teaching, gradually replacing, eliminating and modifying the teaching materials that are not suitable for the current engineering undergraduate education, so that the students can learn from the school and get the knowledge of the future work, the knowledge that the school only needs in the teaching work, so that the content of the environment monitoring course is kept abundant and more practical. In order to keep the books up-to-date, it's a good business requirement, and the university of nanjing has written environmental monitoring handouts, and it's been perfected in the process, and it will be published in 2019 as an official textbook.

\subsection{Promote the diversification of classroom teaching forms of environmental monitoring}

The ability to monitor the skill level is a platform to test the level of environmental monitoring skills, and in the course of the race, the program is designed to be guided by the program, which embodies the idea of the teacher, the student, and the student's subjective energy. It is that cent of the students to the centre of the school. the centre of the book is the centre of the "project", and the focus is on the cultivation of the "operation skill" in the classroom, the focus is on the cultivation of the "operation skill", the theoretical knowledge in the practice will be gradually infiltrated, the problems found in practice are theoretically solved, the students are taught in the teaching, the middle school is used, the interests of the students are raised, the students are studying in the course, and the students can be passive in the study of passive learning. The students are mainly engaged in the teaching of heuristic, in which the students' independent thinking ability is developed in a way that focuses on discussions, asks for individual questions, and leaves the topic after class.

\subsection{Promote the improvement of teachers' professional level}

"Kiss it, believe it," [5], teacher's environmental monitoring theory knowledge, experience, skill level, and the degree of conduct is a powerful influence on students, and the training of student operating skills often begins with a professional teacher. In order to improve the skill level of the students, the teachers shall constantly improve their own professional level of environmental monitoring: one is through "new" activities of the old belt, and the teachers who have experience in the process can help the new teachers to grow rapidly by means of transmission, help and tapes, so as to improve the overall level of the professional teachers. The two is in the form of a lecture 
competition to improve the curriculum presentation capability of the teachers and to improve the results of the course construction; Three is by appointing teachers to the environmental protection industry, enterprise monitoring on the line, or invite environmental monitoring line of professional and technical personnel to training, make up for the lack of practical experience of environmental monitoring; Fourthly, through the discussion and training between colleges and universities before the environmental monitoring competition, as well as the observation and evaluation during the competition, teachers from different schools can communicate and learn from each other. Through the role of the window of the competition, teachers have more opportunities to contact with new technologies, environmental protection equipment and environmental monitoring skills and methods of the environmental protection industry and enterprises, which widens their vision and promotes the continuous improvement of teachers' environmental professional level and practical ability.

\subsection{Competition promotes the improvement of students' independent learning ability}

The content of the environmental monitoring skill competition reflects the advanced educational concepts at home and abroad. It tests the individual quality of the students as well as the cooperation level of the participating teams. It requires the participants to be proficient in different monitoring methods and norms, have a solid theoretical foundation, high practical skills, strong organizing and coordinating ability and adaptability, and be able to deal with various emergencies flexibly. It's a way to get the students to spend a lot of time to revise, understand, and reinforce what they know, and in order to adapt to the needs of the race, they need to be taught to expand their knowledge and depth. The team members have been constantly training to improve the chemistry of each other, to make up for each other, to enhance the overall level of the team. In the course of 2016 and 2018 , the city of the province of the province of anelei has been involved in all aspects of the design and experimental skills of the experimental skills of the experiment, so the school contestants have given up the rest of the class and the holiday, and they've been training for a long time, and they've done a thousand and a thousand theoretical tests and samples, capacity analysis, and equipment analysis and training programs. In the process of training, mutual supervision, mutual discussion between the team members, team members got great progress, pay a return, also made great achievement in the process of competition, each year, three people to play, are the special one, 1 first prize, second prize 1. Through the holding of environmental monitoring skill competition, it is found that the contestants' autonomous learning ability has been significantly improved, from "I want to learn" to "I want to learn" [6]. In addition, by participating in the competition, students can have more opportunities to contact enterprises, understand the demand for talents in society, and stimulate their enthusiasm for professional learning.

\subsection{Competition for students' comprehensive professional quality of ascension}

Environmental monitoring skill competition is of guiding significance to the improvement of students' comprehensive quality. In the race of environmental monitoring skills, it is required to have a civilized race, a good faith game, and it's innovative, and the team has to work with each other, and focus on the organization and management of the process, and the overall professionalism of the environmental protection industry is fully represented in the process of environmental monitoring skills. Through the guidance and demonstration role of participating students, it is beneficial to the formation and improvement of professional ethics for students of relevant environmental majors. After entering into work, they can realize the purpose of service industry and enterprises.

\section{Conclusions}

Environmental monitoring skill competition is a carrier, which promotes the construction and reform of environmental monitoring professional courses, improves teachers' teaching level, and provides an opportunity for improving students' environmental monitoring skill level. The construction and reform of the course needs to be updated, and we will continue to incorporate new techniques, new methods, new techniques and so on and so on, we will continue to increase the initiative of independent learning, to enhance the student's ability to self-innovate, to improve the overall vocational quality of students, and this is still a long and arduous task for the engineering schools.

\section{Acknowledgement}

The research is supported by a Project Funded by the brand professional project form Yancheng teachers university (2016), the teaching reform and practice of medicinal chemistry (17YCTCJY011) 、 (12YCTCJY011)and A Project Funded by the Excellent Specialties Program Development of Jiangsu Higher Education Institutions (PPZY2015B113). 


\section{References}

[1]Pei-Chi Huang, Juan Wang. (2011). Exploration on vocational education curriculum reform under the background of skill competition: based on jiangsu province chemical inspection skill competition [J]. Journal of xinjiang vocational education research. 19(4):36-37.

[2]Zeng-Fu Xin, Jun-Lu Jin. (2011).Discussion on the intensive training and teaching model of vocational skill competition [J]. Journal of petroleum education,34(6):8-11.

[3]Ning Li, Min Fu, Sheng-Ming Chen, et al. (2012). The promoting effect of chemical engineering design competition on the teaching reform of chemical engineering courses [J]. Journal of science of teachers'college and university.33(1):94-96.

[4]Xiao-Hua Zhang, Chen-Song Zhu, Chang-Ping Zhu. (2011).Subject competition to promote the electrical course teaching reform [J]. Journal of Laboratory research and exploration.(6):278-280.

[5]Qin Fu. (2012). Thoughts triggered by educational skill competition: a study on countermeasures to improve the educational skills of art normal university students [J]. Journal of laboratory research and discovery.30(2):20-23. [6]Sheng-Ming Li.( 2012). Improving the training level of skilled personnel through skill competition [J]. Journal of vocational education BBS.28 (5):55-56. 